\title{
Characterization and prevalence of severe primary IGF1 deficiency in a large cohort of French children with short stature
}

\author{
R Teissier1, I Flechtner ${ }^{1}$, A Colmenares ${ }^{1}, K_{\text {Lambot-Juhan }}^{2}$, G Baujat ${ }^{3}$, C Pauwels $^{1}$, \\ D Samara-Boustani ${ }^{1}$, J Beltrand ${ }^{1}$, A Simon ${ }^{1}$, C Thalassinos ${ }^{1}$, H Crosnier ${ }^{4}$, H Latrech ${ }^{5}$, \\ G Pinto', M Le Merrer ${ }^{3}$, V Cormier-Daire ${ }^{3,6}$, J C Souberbielle ${ }^{7}$ and M Polak ${ }^{1,8}$ \\ ${ }^{1}$ Pediatric Endocrinology, Diabetology and Gynecology Unit, Centre des Maladies Endocriniennes Rares de la \\ Croissance, ${ }^{2}$ Pediatric Radiology Unit and ${ }^{3}$ Department of Medical Genetics, Hôpital Necker Enfants-Malades, \\ Assistance Publique-Hôpitaux de Paris (AP-HP), 149 Rue de Sèvres, 75743 Paris Cedex 15, France, ${ }^{4}$ Pediatric Unit, \\ Centre Hospitalier Intercommunal de Poissy-Saint-Germain-en-Laye, Saint-Germain-en-Laye, France, ${ }^{5}$ Oujda \\ University Hospital, Oujda, Morocco, ${ }^{6}$ INSERM U871, Université Paris Descartes, Sorbonne Paris Cité, Paris, France, \\ ${ }^{7}$ Hormonal Biochemistry Unit, Hôpital Necker Enfants-Malades, Assistance Publique-Hôpitaux de Paris (AP-HP), \\ Paris, France and ${ }^{8}$ INSERM U845, Université Paris Descartes, Sorbonne Paris Cité, Paris, France
}

\author{
Correspondence \\ should be addressed \\ to M Polak \\ Email \\ michel.polak@nck.aphp.fr
}

\begin{abstract}
Objective: The prevalence of severe primary IGF1 deficiency (IGFD) is unclear. IGFD must be identified promptly as treatment with recombinant human IGF1 (rhIGF1) is now available. Our objective was to characterize and assess the prevalence of severe primary IGFD in a large cohort of patients evaluated for short stature at a pediatric endocrinology unit in France. Design: Observational study in a prospective cohort.

Methods: Consecutive patients referred to our unit between 2004 and 2009 for suspected slow statural growth were included. Patients were classified into eight etiological categories. IGFD was defined by height $\leq-3$ SDS, serum IGF1 levels $<2.5$ th percentile, GH sufficiency, and absence of causes of secondary IGFD.

Results: Out of 2546 patients included, 337 (13.5\%) were born small for gestational age and 424 (16.9\%) had idiopathic short stature. In these two categories, we identified 30 patients who met our criterion for IGFD (30/2546, 1.2\%). In these 30 patients, we assessed the response to IGF1 generation test, time course of IGF1 levels, and efficiency of GH replacement therapy. The results indicated that only four of the 30 children were definite or possible candidates for rhIGF1 replacement therapy.

Conclusion: The prevalence of severe primary IGFD defined using the standard criterion for rhIGF1 treatment was $1.2 \%$, and only $0.2 \%$ of patients were eligible for rhIGF1 therapy.
\end{abstract}

\section{Introduction}

Target gene knockout experiments in laboratory animals and the identification of mutations in humans have established a key role for insulin-like growth factor 1 (IGF1) in growth, both in utero and after birth $(1,2)$. IGF1 deficiency (IGFD) can be caused by various conditions including growth hormone (GH) deficiency, nutritional deficiencies, and chronic inflammatory diseases $(3,4,5)$. However, IGFD may occur as a primary disorder, with no identifiable cause. Hormone replacement therapy is widely used in many endocrine diseases, and a recombinant human form of IGF1 (rhIGF1) is now available.

Treatment with rhIGF1 was first used in children with severe primary IGFD caused by insensitivity to GH (Laron syndrome, IGF1 gene mutations, or GH-neutralizing antibodies) $(6,7,8)$. Add-on rhIGF1 therapy improved the growth rate and final height of these patients who (c) 2014 European Society of Endocrinology Printed in Great Britain
Published by Bioscientifica Ltd. 
were not eligible for GH therapy. These results led European authorities to license rhIGF1 for severe primary IGFD with height $\leq-3$ SDS, serum IGF1 levels $<2.5$ th percentile, GH sufficiency, and absence of causes of secondary IGFD (malnutrition, hypothyroidism, etc.).

However, because of the very specific phenotype of the patients enrolled in the initial studies, uncertainty remained regarding the number of children likely to benefit from rhIGF1 therapy. In addition, the prevalence of severe primary IGFD has varied across studies $(9,10,11)$.

Our aim here was to characterize and determine the prevalence of severe primary IGFD meeting criteria for rhIGF1 supplementation in a large prospective cohort of children evaluated at a pediatric endocrinology unit. We also described the treatment and outcomes of these patients.

\section{Subjects and methods}

\section{Study cohort}

To establish our cohort, we prospectively collected the clinical data of all children from the general population observed for suspected slow statural growth at our pediatric endocrinology unit between 1st January 2004 and 31st December 2009. We collected data regarding the height of both parents; the child's medical history (including birth measurements, and medical and surgical conditions); height, weight, BMI, and pubertal status; laboratory findings including IGF1 levels; and bone age and results of screening for constitutional skeletal dysplasia (CSD). We excluded adopted patients (for whom no data were available on birth measurements or biological parents heights) and patients with missing data.

The patients were classified into eight etiological groups (see below). In patients with idiopathic short stature (ISS) and those with a history of being small for gestational age (SGA), a skeletal survey was performed to look for CSD, provided the parents gave their informed consent to this additional investigation.

\section{Methods}

Length and birth weight were expressed in S.D. values with reference to Usher \& McLean (12). Weight, height, and genetic target height were expressed in S.D. with reference to the growth curves of the French population established by Sempe \& Roy-Pernot (13). Genetic target height is the mean parental height $\pm 6.5 \mathrm{~cm}$ (depending on the sex of the child). BMI computed as body weight in kilograms over height in meters squared was expressed as BMI SDS with reference to French curves (14). Pubertal status was defined according to Tanner (15) and the bone age was estimated using the Greulich and Pyle atlas (16).

To measure serum IGF1 levels, an IRMA (IGF-I RIACT, CIS Bio International, Gif sur Yvette, France) was used, except between 30th May 2005 and 8th February 2006, when an automated immunochemiluminometric assay was used instead (IGF-I Advantage, Nichols Institute Diagnostics, San Clemente, CA, USA). Both assays involve acidification to displace IGF1 from its binding proteins followed by the addition of an excess of IGF2. Inter- and intra-assay coefficients of variation were $<5$ and $<6 \%$ respectively for both assays. In our laboratory, the limit of quantification was estimated to be $5 \mathrm{ng} / \mathrm{ml}$ with the IRMA and $10 \mathrm{ng} / \mathrm{ml}$ with the chemiluminometric assay. The concentrations measured using these two assays correlated strongly with each other.

One of the criteria for suspected IGFD is persistent circulating IGF1 levels below the 2.5th percentile of the distribution for age and, when appropriate, pubertal stage. The reference values for serum IGF1 levels were obtained from 168 prepubertal normal children aged $6.0 \pm 3.3$ years whose heights and weights were within 2 s.D. of the normal age-corresponding mean and whose growth velocities during the preceding year were normal (17).

In patients with IGFD, plasma IGF1 levels were measured once or twice a year and considered normalized if above the 2.5 th percentile. IGF1 levels were expressed as $Z$-scores for chronological age, sex, and pubertal stage, as partly described in a previous study (18). For patients with criteria of rhIGF1 treatment, a low-dose IGF1 generation test $(25 \mu \mathrm{g} / \mathrm{kg}$ per day for 4 days, totally $100 \mu \mathrm{g} / \mathrm{kg}$ ) was performed with plasma IGF1 assays before the first injection and on day 5. The poor response to GH was defined as an inability to generate IGF1 levels above $100 \mathrm{ng} / \mathrm{ml}$ (19). It is important to notice that the IGF1 generation test is not necessary to propose a rhIGF1 supplementation in the French legislation.

Replacement therapy with rhGH was almost used in two identified indications of rhGH according to the wellestablished diagnostic criteria: GH deficiency and SGA. Efficacy was assessed during the first treatment year based on the following criteria: i) good height velocity response (defined as height velocity above the mean -1 s.D. on the ISS curve according to gender (20) or height velocity between 7 and $11.4 \mathrm{~cm}$ (10th-90th percentiles) for SGA children (21)); and ii) good height response (defined as height gain $>0.5$ s.D.) (22); plus iii) (if available) 
normalization of IGF1 levels to the normal range for chronological age and pubertal stage.

\section{Classification of the patients}

Patients were classified into eight categories according to the following criteria: i) normal growth (height within \pm 2 S.D.); ii) transient prepubertal slowing of growth with resumption of normal growth velocity at puberty onset; iii) endocrine diseases such as GH deficiency, hypothyroidism, Cushing's syndrome, gonadotropin deficiency, and premature ovarian failure; iv) SGA defined as length and/or weight at birth $\leq-2$ s.D.; v) genetic syndromes (abnormal gene test results or multiple birth defects); vi) adverse effects on growth of a chronic disease or of medications; vii) abnormal growth related to previously diagnosed CSD; and viii) ISS, defined as height $\leq-2$ s.D. with no identified etiology.

\section{Results}

\section{Study cohort}

Between 1st January 2004 and 31st December 2009, 2546 patients were evaluated for suspected slow statural growth, including 1441 (56.6\%) boys. Mean age at the first visit to our unit was 9.5 years (range, 0.02-21.3 years). All the patients were prepubertal. We excluded 34 adopted patients and 16 patients with missing data. Each of the remaining 2496 patients was evaluated and classified as one of the eight above-described categories (Fig. 1): 611 (24.5\%) patients had normal growth, 432 (17.3\%) had transient prepubertal slowing of growth, 298 (12\%) had endocrine diseases, 337 (13.5\%) were born SGA, 223 (8.9\%) had genetic syndromes (including 34 with Turner's syndrome), 126 (5.1\%) had chronic illnesses, 45 (1.8\%) had previously diagnosed CSD, and 424 (16.9\%) had ISS.

\section{Description of patients with potential IGFD}

Overall, 30 of the 2496 patients (1.2\%) met the four criteria for rhIGF1 treatment (i.e. height $\leq-3$ s.D., serum IGF1 levels $<2.5$ th percentile, GH sufficiency, and absence of causes of secondary IGFD). After exclusion of the 312 patients deemed to have normal growth, the prevalence was $1.6 \%(30 / 1884)$. All 30 patients were in the ISS or SGA categories, that corresponding to a IGFD prevalence at $3.9 \%$ (30/768), and $2.5 \%$ among the ISS children, as the other categories implied the presence of another cause of short stature (with or without low IGF1 levels): 11 children

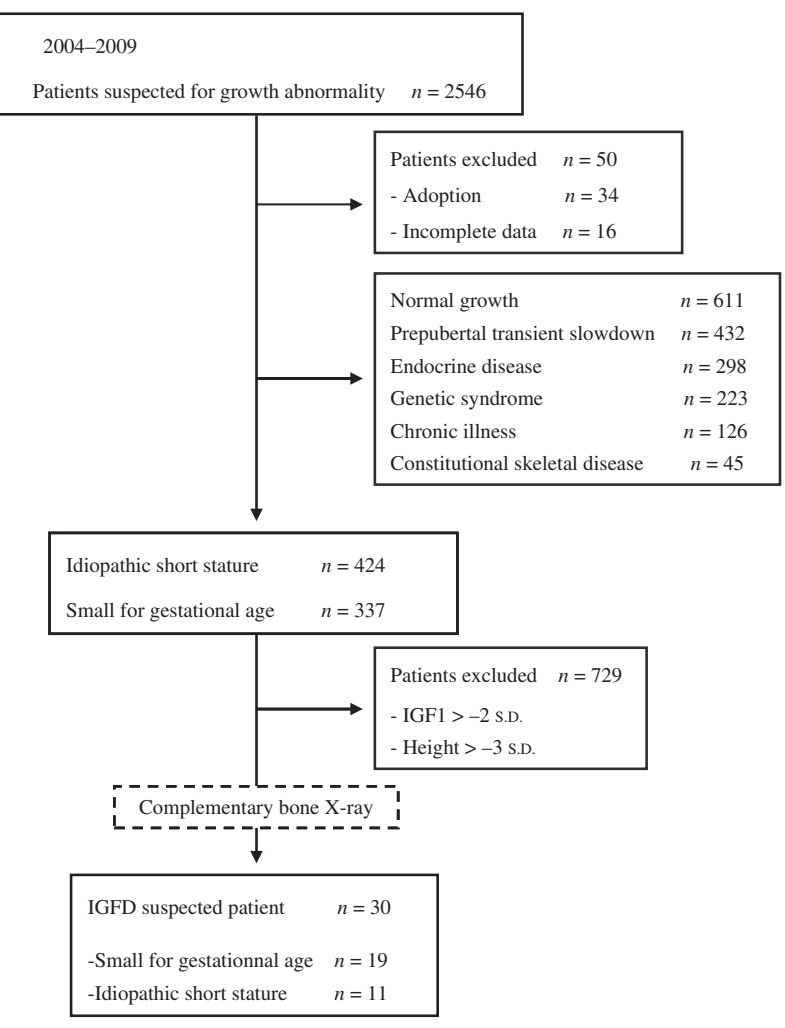

\section{Figure 1}

Identification of patients with severe primary IGF1 deficiency.

had ISS and 19 were born SGA without catch-up growth to above -2 s.D. at first evaluation (Fig. 2).

\section{Follow-up of patients with IGFD}

We used clinical and laboratory data to classify these 30 patients into five groups (Table 1).

Spontaneous normalization of IGF1 levels and/or growth $(n=7) \bullet$ IGF1 levels and/or growth returned to normal spontaneously in seven children. Among them, two (patients \#1 and \#2) were born SGA and normalized their growth (height within \pm 2 s.D.) but not their IGF1 levels, with no change in BMI. Of the remaining five patients (\#3 through \#7), four normalized their IGF1 levels but not their growth within \pm 2 s.D. and one (\#6) had both a return to normal of IGF1 levels and catch-up growth from -3.3 to -1.2 s.D. Of these five patients, two (\#4 and \#5) were underweight (BMI $<-2$ s.D.) and one (\#5) normalized his BMI from -2.8 to $+1.1 \mathrm{Zs}$. Moreover, in patient \#5, the IGF1 generation test showed IGF1 elevation after 4 days of rhGH replacement therapy; this patient has been scheduled for rhGH replacement therapy. 


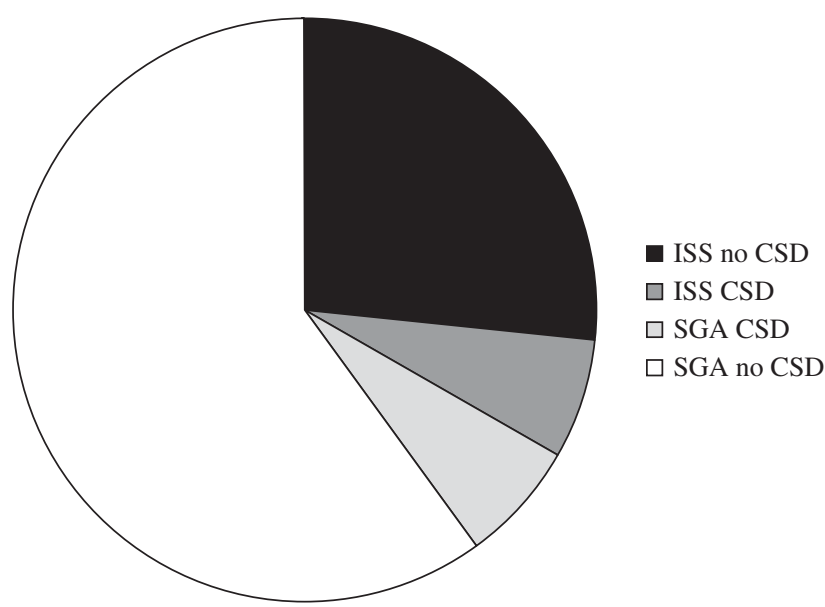

Figure 2

Classification of the 30 patients with possible IGF1 deficiency (IGFD) according to birth measurements. CSD, constitutional skeletal dysplasia; SGA, small for gestational age; ISS, idiopathic short stature; BM, birth measurements.

Replacement therapy with rhGH $(n=15)>$ Out of 15 children treated with rhGH, 12 (\#8-\#19) showed a good clinical response including ten with a good laboratory response. Out of these 12 patients, seven (\#8-\#14) were born SGA. The remaining five good responders had ISS; two of them (\#17 and \#19) were treated when an IGF1 generation test showed IGF1 elevation after 4 days of rhGH replacement therapy and the other three (\#15, \#16, and \#17) were treated at the request of the physician and with the prior agreement of the statutory health insurance authority (no agreement of replacement GH therapy for ISS in France) to evaluate the potential efficacy of rhGH replacement therapy in ISS.

The three nonresponders (\#20, \#21, and \#22) were born SGA. Among them, two showed a BMI decrease during rhGH replacement therapy; for the remaining one patient (\#20), no cause of rhGH nonresponding treatment was identified. Surprisingly, despite major feeding difficulties, patient \#21 had normalization of her IGF1 levels during rhGH replacement therapy, a fact that argued strongly against IGFD. In patient \#22, whose BMI decreased, poor treatment adherence was reported by the family, suggesting that the absence of a response was due to inadequate rhGH exposure and not to IGFD.

Skeletal dysplasia $(n=4) \triangleright$ The radiographic survey showed evidence of skeletal dysplasia in four children. The diagnoses were polyepiphyseal dysplasia (\#23), metaphyseal dysplasia (\#24), SHOX-like syndrome (\#25), and acrocapitofemoral dysplasia (\#26). Out of these four patients, two were born SGA (\#23 and \#26) and three (\#23, \#24, and \#25) had at least one parent with a height $\leq-2$ s.D.

IGFD $(n=2) \vee$ IGFD was documented in two children, one with no response to the IGF1 generation test and one with Laron syndrome. The first child (\#27) was born from nonconsanguineous parents and had intrauterine growth restriction (birth weight, -2.3 s.D.). He was referred to our unit at the age of 7 years for growth retardation ( -3 s.D.). An IGF1 generation test showed no response (IGF1 change from 42 to $54 \mathrm{ng} / \mathrm{ml}$ (<-3 s.D.)). Molecular studies failed to identify a $\mathrm{GH}$ receptor gene mutation. The parents declined rhIGF1 replacement therapy. The patient is now 10 years old, his growth velocity is settled on the -3 s.D. curve, and his IGF1 levels remain low at $-3 \mathrm{Zs}$. The second child (\#28) was born from consanguineous parents and was referred for major growth retardation (height -9.2 S.D.) and typical dysmorphic features of GH deficiency (high prominent forehead, hypoplastic nasal bridge, and acromicria). Molecular studies identified a homozygous exon 7 mutation indicating Laron syndrome. Replacement therapy with rhIGF1 started at 14 months of age resulted in good catch-up growth $(+9.8 \mathrm{~cm} /$ year $)$ with an improvement in height $(+1.3$ s.D./year).

Patients lost to follow-up $(n=2) \triangleright$ Two children (\#29 and \#30) were lost to follow-up. Overall, two children were identified with severe primary IGFD indicating that they might benefit from rhIGF1 treatment. Among the three children who did not respond to GH supplementation, one had IGF1 level normalization, which nearly ruled out IGFD. Thus, four children were candidates for rhIGF1 treatment.

\section{Discussion}

The prevalence of severe primary IGFD remains unclear. Previous studies showed prevalences ranging from 11 to $25 \%(9,10,11)$ but used different definitions and source populations. We defined severe primary IGFD based on criteria for rhIGF1 replacement therapy and found much lower prevalences of $1.2 \%$ overall and $2.5 \%$ among the ISS children. However, in a study of prepubertal children with isolated short stature defined as height $\leq-2$ s.D., the subgroup with height $\leq-3$ s.D. (the criterion for short stature used in our study) had a prevalence of IGFD of only $0.8 \%(n=3 / 362)$, similar to our result (Table 2$)$. 


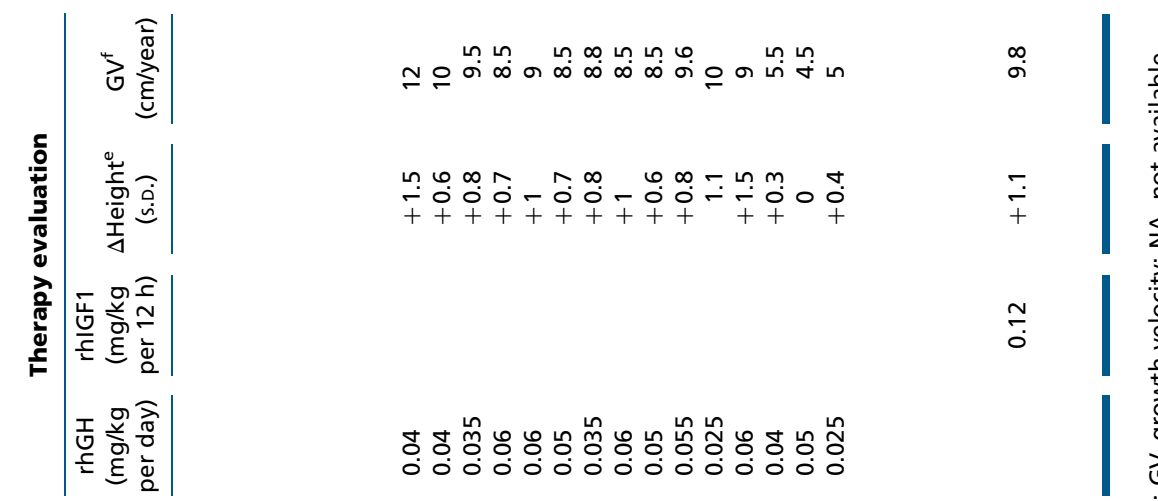

花兽|

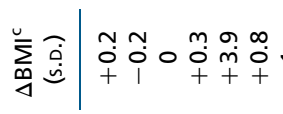

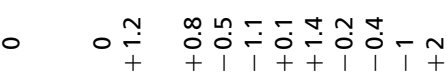

专学

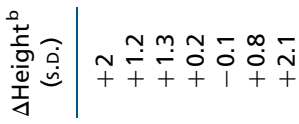

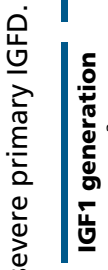

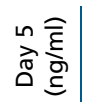

$\stackrel{\infty}{\sim}$

กั้ นั

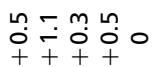

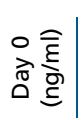

官

$\pm \bar{m}$

เก

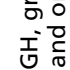

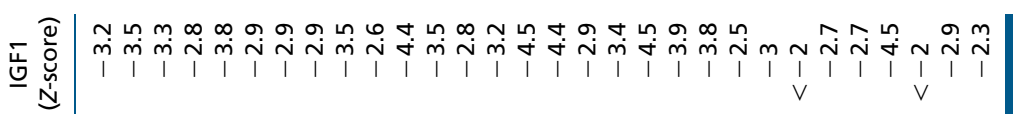

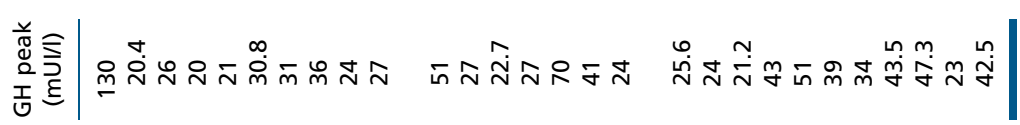

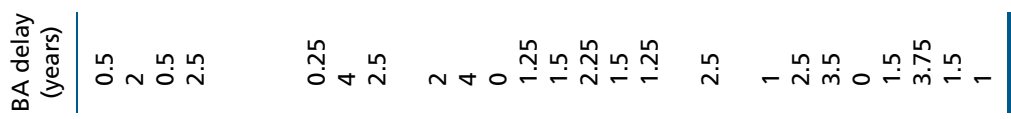

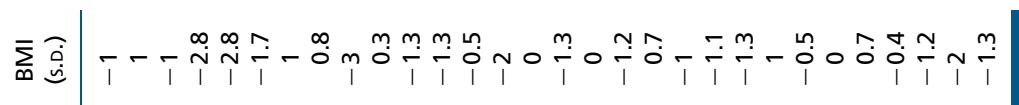

晜

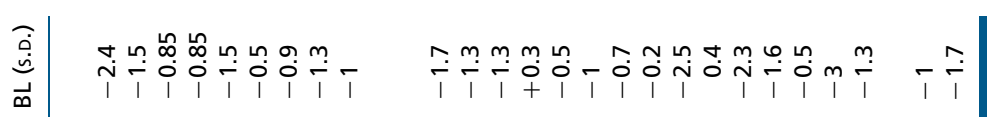

总|

还旁

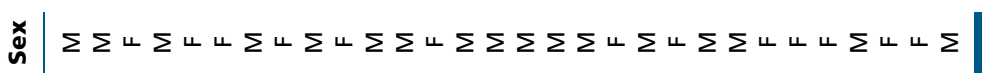

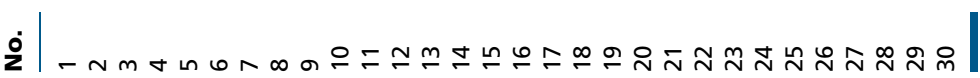

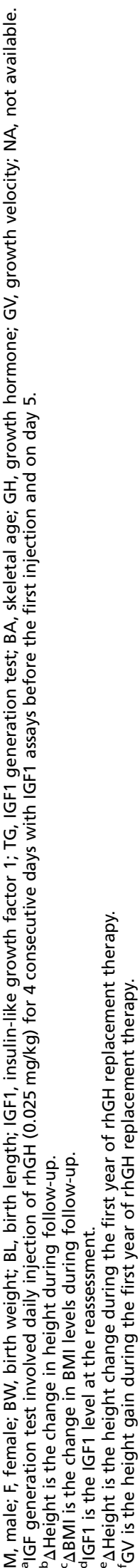


Table 2 Prevalence of IGF1 deficiency (IGFD) according to studies and inclusion criteria.

\section{References}

(10)

(9)

Our cohort

\begin{tabular}{l} 
Inclusion criteria \\
\hline Height $\leq-2$ s.D. \\
IGF $\leq-2$ s.D. \\
Height $\leq-2$ s.D. \\
IGF $1<-3$ S.D. \\
Height $\leq-2.5$ s.D. \\
IGF $1 \leq-2$ s.D. \\
Height $\leq-3$ s.D. \\
IGF $1<2.5$ th percentile
\end{tabular}

\begin{tabular}{ccc}
\hline Prevalence 1 (\%) & & Prevalence 2 (\%) \\
\cline { 1 - 2 } & NA \\
20 & 0.8 \\
11.2 & 1.2 \\
\hline
\end{tabular}

Prevalence 1 is the prevalence found in the study; prevalence 2 is the prevalence in the study subgroup with height $\leq-3$ s.D. and IGF1 level $<2.5$ th percentile; NA, not available.

Depending on the study, short stature is defined as height $\leq-2$ or $\leq-3$ s.D. We chose height $\leq-3$ s.D., which is among the criteria for rhIGF1 treatment. French reference curves for height were established in 1979. As height increases from one generation to the next (e.g. by $1.5 \mathrm{~cm} / 10$ years in The Netherlands (23)), our study probably underestimated the number of children with short stature. Updated reference curves for the French population are needed. Finally, obstacles to comparisons of the prevalence of IGFD include the lack of precision of the case definition (24) and the absence in most patients of molecular confirmation of the diagnosis (25).

To assess the number of children eligible for rhIGF1 treatment, we evaluated the time course of the abnormalities. In five children, IGF1 levels returned to normal spontaneously. Many factors affect IGF1 levels (26), and a single IGF1 assay is not sufficient to establish a diagnosis of IGFD. In addition, there is no international standard regarding the assay method or sample collection and storage procedures (27), and intra-individual variations in IGF1 levels consistent with variability across assay methods have been reported (28). Finally, IGF1 levels in the bloodstream do not reflect the paracrine and autocrine activity of IGF1, which exerts a major effect on growth velocity (29). Thus, the interpretation of IGF1 levels is difficult. One of the five children experienced BMI normalization, which might explain the spontaneous IGF1 level normalization (30). One study showed that children with ISS were picky eaters who manifested little enjoyment of food and were soon satisfied. These patients had BMI values that were within the normal range but lower than that in controls (31). Before considering a diagnosis of IGFD, weight deficiencies should be corrected and dietary intakes assessed to eliminate malnutrition, a cause of secondary IGFD. In our study, two of the three patients who failed to respond to rhGH therapy had decreases in BMI during the treatment, a factor that further emphasizes the major role for nutritional status on growth and the need to correct any nutritional deficiencies. In addition, a previous study established that a satisfactory increase in IGF1 levels during rhGH replacement therapy occurred only in well-nourished children (32).

In our study, rhGH therapy was effective in seven children born SGA, in keeping with earlier data (32). In addition, five children with ISS responded to rhGH therapy, including two with positive IGF1 generation tests. A study in children with ISS showing an increased final height in children with ISS given long-term rhGH therapy (33) led to licensing of rhGH in this indication in several countries. In France, however, rhGH is not approved for the treatment of ISS, and no treatment is available for children with ISS who do not meet criteria for rhIGF1 therapy.

Three further investigations may provide additional diagnostic and therapeutic advances. First, in patients diagnosed with IGFD, IGF-binding protein 3 and GH-binding protein (GHBP (GHR)) should be assayed, and molecular tests should be done to assess genes such as the GH receptor (GHR) gene and IGF1 gene (34). Secondly, studies on nocturnal GH release in patients with normal peak GH secretion but with slowdown stature might allow the identification of GH neurosecretory dysfunction, a condition that might respond to rhGH therapy. GH neurosecretory dysfunction is not sought routinely but may explain the good response to rhGH seen in some children with ISS (35). Finally, the IGF1 generation test, despite its limitations (36), might provide useful therapeutic guidance by helping to predict the response to rhGH.

Out of our 30 patients with potential severe primary IGFD, four had skeletal dysplasias diagnosed by routine skeletal surveys. A diagnosis of CSD may be an argument 
against the use of rhIGF1, as well as of rhGH in some cases with a mild or absent significant effect on height and the possibility to observe serious adverse effects (37).

Treatment with rhIGF1 has proven effective in patients with GH insensitivity. Growth rates increased by $5.4-6.1 \mathrm{~cm} /$ year according to the dosage $(80 \mu \mathrm{g} / \mathrm{kg}-$ $120 \mu \mathrm{g} / \mathrm{kg}$ per $12 \mathrm{~h}$ ) (38). A single study evaluated the efficacy of rhIGF1 given for 1 year to children with ISS (8). These results indicate a need for caution regarding several points such as the mean IGF1 SDS increases of +2 $(80 \mu \mathrm{g} / \mathrm{kg})$ or $+2.2(120 \mu \mathrm{g} / \mathrm{kg})$, i.e. at the upper limit of international recommendations (39); accelerated bone maturation compared with the control group (1.1 and 1.2 vs 0.8 years), and a significantly greater number of children entering puberty (12 vs 1 ). However, this study (8) demonstrates the efficacy of rhIGF1, with a growth rate increase in both dosage groups ( 7 and 7.9 vs $5.2 \mathrm{~cm} /$ year in controls) and increased height $(+0.4$ and +0.5 s.D. vs 0.02 S.D. in controls). Similar results were reported after 1 year of rhGH therapy in children with ISS (40). It would have been of interest to compare the two rhIGF1 dosages with rhGH instead of untreated controls. Nevertheless, if the preliminary results with rhIGF1 are promising, particularly as no other treatment options are available to date under certain conditions, it remains important to consider the use of rhGH in first line, especially in children with SGA.

The prevalence of severe primary IGFD defined using criteria for rhIGF1 treatment was only $1.2 \%$ in a vast cohort of children with short stature. Thus, the number of patients eligible for rhIGF1 therapy is small. Nevertheless, the efficacy of rhIGF1 in carefully selected patients is important to note, as no other effective treatments are available.

\section{Declaration of interest}

The authors declare that there is no conflict of interest that could be perceived as prejudicing the impartiality of the research reported.

\section{Funding}

This study was supported by an educational grant from IPSEN SAS. In compliance with the Uniform Requirements for Manuscripts, established by the International Committee of Medical Journal Editors, the sponsor of this study did not impose any impediment, directly or indirectly, on the publication of the study's results.

\section{Acknowledgements}

We thank the IPSEN staff in Paris for supporting our study.

\section{References}

1 Liu JP, Baker J, Perkins AS, Robertson EJ \& Efstrtiadis A. Mice carrying null mutations of the genes encoding insulin-like growth factor I (IGF1) and type 1 IGF receptor (Igf1r). Cell 199375 59-72.

2 Walenkamp MJ \& Wit JM. Genetic disorders in the growth hormone insulin-like growth factor I axis. Hormone Research 200666 221-230. (doi:10.1159/000095161)

3 Sugisaki T, Yamada T, Takamatsu K \& Noguchi T. The influence of endocrine factors on the serum concentrations of insulin-like growth factor-I (IGF-I) and IGF-binding proteins. Journal of Endocrinology 1993 138 467-477. (doi:10.1677/joe.0.1380467)

4 Thissen JP, Ketelslegers JM \& Underwood LE. Nutritional regulation of the insulin-like growth factors. Endocrine Reviews 199415 80-101.

5 Grote FK, Van Suijlekom-Smit LW, Mul D, Hop WC, Ten Cate R, Oostdijk W, Van Luijk W, Jansen-van Wijngaarden CJ \& De Muinck Keizer-Schrama SM. Growth hormone treatment in children with rheumatic disease, corticosteroid induced growth retardation, and osteopenia. Archives of Disease in Childhood 200691 56-60. (doi:10. 1136/adc.2004.069138)

6 Backeljauw PF \& Chernausek SD. Treatment of insulin-like growth factor deficiency with IGF-I: studies in humans. Hormone Research 2006 65 (Suppl 1) 21-27. (doi:10.1159/000090643)

7 Chernausek SD, Backeljauw PF, Frane J, Kuntze J, Underwood LE \& for the GH Insensitivity Syndrome Collaborative Group . Long-term treatment with recombinant insulin-like growth factor (IGF)-I in children with severe IGF1 deficiency due to growth hormone insensitivity. Journal of Clinical Endocrinology and Metabolism 200792 902-910. (doi:10.1210/jc.2006-1610)

8 Midyett LK, Rogol AD, Van Meter QL, Frane J, Bright GM \& MS301 Study Group . Recombinant insulin-like growth factor (IGF)-I treatment in short children with low IGF-I levels: first-year results from a randomized clinical trial. Journal of Clinical Endocrinology and Metabolism 201095 611-619. (doi:10.1210/jc.2009-0570)

9 Edouard T, Grünenwald S, Gennero I, Salles JP \& Tauber M. Prevalence of IGF1 deficiency in prepubertal children with isolated short stature. European Journal of Endocrinology 2009 161 43-50. (doi:10.1530/EJE-080964)

10 Attie KM, Julius JR, Stoppani C \& Rundle AC. National Cooperative Growth Study substudy VI: the clinical utility of growth-hormonebinding protein, insulin-like growth factor I and insulin-like growth factor-binding protein 3 measurements. Journal of Pediatrics 1997131 S56-S60. (doi:10.1016/S0022-3476(97)70013-1)

11 Clayton PE, Ayoola O \& Whatmore AJ. Patient selection for IGF-I therapy. Hormone Research 200665 28-34. (doi:10.1159/000090644)

12 Usher R \& McLean F. Intrauterine growth of live-born Caucasian infants at sea level: standards obtained from measurements in 7 dimensions of infants born between 25 and 44 weeks. Journal of Pediatrics 196975 901-910. (doi:10.1016/S0022-3476(69)80224-6)

13 Sempe MPG \& Roy-Pernot MP. In Auxologie, Mthodes et Squences. Paris: Laboratoire Théraplix, 1979

14 Rolland-Cachera MF, Cole TJ, Sempe M, Tichet J, Rossignol C \& Charraud A. Body mass index variations: centiles from birth to 87 years. European Journal of Clinical Nutrition 1991 45 13-21.

15 Tanner J. In Growth and Adolescence. Oxford: Blackwell, 1969.

16 Greulich W. In Radiographic Atlas of Skeletal Development of the Hand and Wrist. Stanford: University Press, 1959.

17 Bussières L, Souberbielle JC, Pinto G, Adan L, Noel M \& Brauner R. The use of insulin-like growth factor 1 reference values for the diagnosis of growth hormone deficiency in prepubertal children. Clinical Endocrinology 200052 735-739. (doi:10.1046/j.1365-2265.2000.00999.x)

18 Léger J, Mercat I, Alberti C, Chevenne D, Armoogum P, Tichet J \& Czernichow P. The relationship between the GH/IGF-I axis and serum markers of bone turnover metabolism in healthy children. European Journal of Endocrinology 2007157 685-692. (doi:10.1530/EJE-07-0402) 
19 Buckway CK, Guevara-Aguirre J, Pratt KL, Burren CP \& Rosenfeld RG. The IGF-I generation test revisited: a marker of GH sensitivity. Journal of Clinical Endocrinology and Metabolism 200186 5176-5183. (doi:10.1210/ jcem.86.11.8019)

20 Bang P, Bjerknes R, Dahlgren J, Dunkel L, Gustafsson J, Juul A, Kriström B, Tapanainen P \& Aberg V. A comparison of different definitions of growth response in short prepubertal children treated with growth hormone. Hormone Research in Paediatrics 201175 335-345. (doi:10.1159/000322878)

21 Bakker B, Frane J, Anhalt H, Lippe B \& Rosenfeld RG. Height velocity targets from the national cooperative growth study for first-year growth hormone responses in short children. Journal of Clinical Endocrinology and Metabolism 200893 352-357. (doi:10.1210/ jc.2007-1581)

22 Ranke MB, Lindberg A, Cowell CT, Wikland KA, Reiter EO, Wilton P, Price DA \& on behalf of the KIGS International Board. Prediction of response to growth hormone treatment in short children born small for gestational age: analysis of data from KIGS (Pharmacia International Growth database). Journal of Clinical Endocrinology and Metabolism 2003 88 125-131. (doi:10.1210/jc.2002-020867)

23 Wit JM. Idiopathic short stature: reflections on its definition and spontaneous growth. Hormone Research 200767 (Suppl 1) 50-57. (doi:10.1159/000097553)

24 Ranke MB. Defining insulin-like growth factor-1 deficiency. Hormone Research 200665 (Suppl 1) 9-14. (doi:10.1159/000090641)

25 Cohen P. Problems with reclassification of insulin-like growth factor I production and action disorders. Journal of Clinical Endocrinology and Metabolism 200691 4235-4236. (doi:10.1210/jc.2006-1641)

26 Ranke MB, Feldt-Rasmussen U, Bang P, Baxter RC, Camacho-Hübner C, Clemmons DR, Juul A, Orskov H \& Strasburger CJ. How should insulin-like growth factor I be measured? A consensus statement. Hormone Research 200155 (Suppl 2) 106-109. (doi:10.1159/ 000063485)

27 Frystyk J, Freda P \& Clemmons DR. The current status of IGF-I assays - a 2009 update. Growth Hormone \& IGF Research 201020 8-18. (doi:10.1016/j.ghir.2009.09.004)

28 Milani D, Carmichael JD, Welkowitz J, Ferris S, Reitz RE, Danoff A \& Kleinberg DL. Variability and reliability of single serum IGF-I measurements: impact on determining predictability of risk ratios in disease development. Journal of Clinical Endocrinology and Metabolism 200489 2271-2274. (doi:10.1210/jc.2003-032150)

29 Yakar S, Liu JL, Stannard B, Butler A, Accili D, Sauer B \& LeRoith D. Normal growth and development in the absence of hepatic insulin-like growth factor I. PNAS 199996 7324-7329. (doi:10.1073/pnas.96.13. 7324)

30 Merimee TJ, Zapf J \& Froesch ER. Insulin-like growth factors in the fed and fasted states. Journal of Clinical Endocrinology and Metabolism 1982 55 999-1002. (doi:10.1210/jcem-55-5-999)
31 Wudy SA, Hagemann S, Dempfle A, Ringler G, Blum WF, Berthold LD, Alzen G, Gortner L \& Hebebrand J. Children with idiopathic short stature are poor eaters and have decreased body mass index. Pediatrics 2005116 52-57. (doi:10.1542/peds.2004-1684)

32 Van Pareren Y, Mulder P, Houdijk M, Jansen M, Reeser M \& HokkenKoelega A. Adult height after long-term, continuous growth hormone $(\mathrm{GH})$ treatment in short children born small for gestational age: results of a randomized, double-blind, dose-response GH trial. Journal of Clinical Endocrinology and Metabolism 200388 3584-3590. (doi:10.1210/ jc.2002-021172)

33 Hintz RL, Attie KM, Baptista J \& Roche A \& for the Genentech Collaborative Group. Effect of growth hormone treatment on adult height of children with idiopathic short stature. New England Journal of Medicine 199918 502-507. (doi:10.1056/ NEJM199902183400702)

34 Hindmarsh PC. Standard and low-dose IGF1 generation tests and spontaneous growth hormone secretion in children with idiopathic short stature. Commentary. Clinical Endocrinology 200460 161-162. (doi:10.1111/j.1365-2265.2004.01958.x)

35 Savage MO, Camacho-Hübner C, David A, Metherell LA, Hwa V, Rosenfeld RG \& Clark AJ. Idiopathic short stature: will genetics influence the choice between GH and IGF-I therapy? European Journal of Endocrinology 2007157 (Suppl 1) S33-S37. (doi:10.1530/EJE-07-0292)

36 Coutant R, Dörr HG, Gleeson H \& Argente J. Diagnosis of endocrine disease: limitations of the IGF1 generation test in children with short stature. European Journal of Endocrinology 2012166 351-357. (doi:10.1530/EJE-11-0618)

37 Kanazawa H, Tanaka H, Inoue M, Yamanaka Y, Namba N \& Seino Y. Efficacy of growth hormone therapy for patients with skeletal dysplasia. Journal of Bone and Mineral Metabolism 200321 307-310. (doi:10.1007/ s00774-003-0425-7)

38 Guevara-Aguirre J, Rosenbloom AL, Vasconez O, Martinez V, Gargosky SE, Allen L \& Rosenfeld RG. Two-year treatment of growth hormone (GH) receptor deficiency with recombinant insulin-like growth factor-I in 22 children: comparison of two dosage levels and to GH-treated GH deficiency. Journal of Clinical Endocrinology and Metabolism 199782 629-633.

39 Sperling MA, Saenger PH, Hintz R, Wilson T, Rose SR \& Lawson Wilkins Pediatric Endocrine Society \& LWPES Executive Committee and the LWPES Drug and Therapeutics Committee. Growth hormone treatment and neoplasia-coincidence or consequence? Journal of Clinical Endocrinology and Metabolism 200287 5351-5352. (doi:10.1210/jc. 2002-021467)

40 Genentech Collaborative Study Group. Idiopathic short stature: results of a one-year controlled study of human growth hormone treatment. Journal of Pediatrics 1989115 713-719. (doi:10.1016/S00223476(89)80647-X)

Received 10 April 2013

Revised version received 24 March 2013

Accepted 10 April 2014 